\title{
Transcriptional response of Bacillus megaterium FDU301 to PEG200-mediated arid stress
}

Lei Zhao ${ }^{1,2}$, Yanjun Zhou' ${ }^{1}$, Jianbei $\mathrm{Li}^{1}$, Yucheng Xia ${ }^{1}$, Weiyun Wang ${ }^{1}$, Xiuqi Luo ${ }^{1}$, Juan Yin ${ }^{1}$ and Jiang Zhong ${ }^{1,2^{*}}$

\begin{abstract}
Background: For microorganisms on a paper surface, the lack of water is one of the most important stress factors. A strain of Bacillus megaterium FDU301 was isolated from plaques on a paper surface using culture medium with polyethylene glycol 200 (PEG200) to simulate an arid condition. Global transcriptomic analysis of B. megaterium FDU301 grown under normal and simulated arid conditions was performed via RNA-seq technology to identify genes involved in arid stress adaptation.

Results: The transcriptome of B. megaterium FDU301 grown in LB medium under arid (15\% PEG200 (w/w)) and normal conditions were compared. A total of 2941 genes were differentially expressed, including 1422 genes upregulated and 1519 genes downregulated under arid conditions. Oxidative stress-responsive regulatory genes perR, fur, and tipA were significantly upregulated, along with DNA protecting protein (dps), and catalase (katE). Genes related to $\mathrm{Fe}^{2+}$ uptake (feoB), sporulation stage II (spollB, spollE, spol/GA), small acid-soluble spore protein $(s s p D)$, and biosynthesis of compatible solute ectoine (ectB, ectA) were also highly expressed to various degrees. Oxidative phosphorylation-related genes ( $a t p B, \operatorname{atp} E, \operatorname{atpF}, \operatorname{atpH}, \operatorname{atp} A, \operatorname{atpG}, \operatorname{atpD}$, atp $C$ ) and glycolysis-related genes ( $p g k$, tpiA, frmA) were significantly downregulated.

Conclusion: This is the first report about transcriptomic analysis of a B. megaterium to explore the mechanism of arid resistance. Major changes in transcription were seen in the arid condition simulated by PEG200 (15\%), with the most important one being genes related to oxidative stress. The results showed a complex mechanism for the bacteria to adapt to arid stress.
\end{abstract}

Keywords: Arid stress, Bacillus megaterium, Polyethylene glycol 200, Transcriptome, RT-qPCR

\section{Background}

Microorganisms are affected by various environmental factors, and successful adaptation to these factors is key for microbial colonization. Arid stress is caused by a lack of water or by high concentration of salts in the environment. However, microbes living in arid deserts, drying

\footnotetext{
* Correspondence: jzhong@fudan.edu.cn

'Department of Microbiology and Microbial Engineering and State Key Laboratory of Genetic Engineering, School of Life Sciences, Fudan University, Shanghai 200438, China

${ }^{2}$ Institute for Preservation and Conservation of Chinese Ancient Books, Fudan University, Shanghai 200433, China
}

foods and plant rhizosphere have developed complicated strategies to survive under arid conditions [1-3].

The water available to living organisms in a sample can be represented by water activity (aw), which is the ratio between the vapor pressure of the sample, and that of distilled water, under the same conditions [4]. Microorganisms require a certain minimum level of water activity to grow normally [5].

Suitable water activity is important for fungal cell morphology and biochemical responses [5, 6]. Under arid stress, the differentiation and division of fungal cells slow down and the metabolism is significantly suppressed $[7,8]$.

(c) The Author(s). 2020 Open Access This article is licensed under a Creative Commons Attribution 4.0 International License, which permits use, sharing, adaptation, distribution and reproduction in any medium or format, as long as you give appropriate credit to the original author(s) and the source, provide a link to the Creative Commons licence, and indicate if changes were made. The images or other third party material in this article are included in the article's Creative Commons licence, unless indicated otherwise in a credit line to the material. If material is not included in the article's Creative Commons licence and your intended use is not permitted by statutory regulation or exceeds the permitted use, you will need to obtain permission directly from the copyright holder. To view a copy of this licence, visit http://creativecommons.org/licenses/by/4.0/ The Creative Commons Public Domain Dedication waiver (http://creativecommons.org/publicdomain/zero/1.0/) applies to the data made available in this article, unless otherwise stated in a credit line to the data. 
Aspergillus spp. and Saccharomyces cerevisiae synthesize and accumulate compatible solutes, such as glycerol, to protect proteins and nucleic acids [9-11]. In response to the lack of water, Xeromyces bisporus and some other food-borne molds have increased amount of saturated fatty acid in their membrane, and form extracellular polymers [12].

Compared to fungi, most bacteria are less adaptable to arid stress. Studies on the adaptation of bacterial to arid condition have mostly been on food-borne pathogens $[13,14]$ and soil bacteria $[15,16]$. Pseudomonas spp. respond to arid stress by secreting polysaccharides and changing the composition of fatty acid to maintain membrane fluidity [15]. Bacteria also synthesize or uptake compatible solutes, such as glycinebetaine, proline, trehalose and ectoine to resist arid stress $[17,18]$. For example, the upregulation of osmoprotectant transporters (proU, osmU, proP) and trehalose biosynthetic genes were found during the Salmonella arid tolerance $[19,20]$. Alternative sigma factors (for example, rpoS) are essential for coordinating $S$. enterica adaptation to arid stress [21]. In addition, iron-sulfur (Fe-S) cluster synthesis-related genes (such as nifU, nifS, iscA, sufD), and virulence factors ( $\operatorname{sop} D$ and $s s e D$ ) are essential for the survival of Salmonella in arid environments [13, 22-25].

Arid stress is known to increase the formation of reactive oxygen species (ROS) in bacteria, leading to lipid peroxidation, protein denaturation and nucleic acid damage [26]. It has been shown that bacteria adapt to the oxidative stress caused by arid environments by accumulating intracellular $\mathrm{Mn}^{2+}$, which is involved in protein protection [27]. SigB activity plays an important role in Staphylococcus aureus adaptation to oxidative stress caused by arid environments [28].

There are relatively few studies on the arid tolerance of Bacillus. In general, Bacillus tolerate arid and osmotic stress by rapidly accumulating compatible solutes or opening channels for ions such as $\mathrm{Na}^{+}$and $\mathrm{K}^{+}$[29]. Forming spore is also a common strategy of Bacillus to survive adverse environments. The transcriptomic response to arid conditions has not been well studied in Bacillus.

In this study, we used polyethylene glycol 200 (PEG200) to simulate arid stress in the medium [30], since PEG200 had no direct role in bacterial physiology and metabolism. A strain of B. megaterium FDU301 adaptable to arid conditions was isolated from a paper surface. Using transcriptome technology (RNA-seq), the gene expressions of $B$. megaterium FDU301 under simulated arid and normal conditions were compared. This work is aimed at offering a new perspective to understand the adaptation of bacteria on paper surface, and to control bacteria-related deterioration of paper documents in the future.

\section{Results}

Characterization of B. megaterium FDU301

A strain of $B$. megaterium tolerant to arid condition (15\% PEG200 (w/w), aw 0.985) was isolated from plaque areas on the surface of a leaflet in an old book, and was named as FDU301. The sequence of its $16 \mathrm{~S}$ rDNA gene was identical to that of $B$. megaterium NBRC15308 and $B$. megaterium QMB1551 (data not shown). The whole genome of B. megaterium FDU301 was sequenced on a combination of Illumina HiSeq and PacBio RSII platforms [31]. The assembled genome was 6,872,701 bp in length, comprising one chromosome and nine plasmids.

Comparing with B. megaterium NBRC15308, FDU301 had a larger genome, and more predicted genes. Under the conditions of amino acid sequence identity being greater than $40 \%$ over at least $80 \%$ of the full sequence length [32], FDU301 and NBRC15308 had 5335 homologous genes. Among 1561 genes unique to FDU301, 305 genes were annotated with KEGG database to be related to signaling and cellular processes, environmental information processing, genetic information processing, carbohydrate metabolism, etc. The full genome data of B. megaterium FDU301 can be found in NCBI GenBank (accession numbers CP045267-CP045276).

As shown in Fig. 1a, FDU301 showed a typical "S" type growth curve in normal LB medium, with an incubation period of $2 \mathrm{~h}$, and reached a plateau around $10 \mathrm{~h}$. In the presence of 5\% PEG200, the FDU301 grew faster and reached higher cell density than that in normal LB medium. As the concentration of PEG200 increased, the growth of bacteria slowed down and reached much lower cell density than that in normal LB medium. The bacteria hardly grew in the medium with 20\% PEG200, indicating the limit of the strain to tolerate. Compared to B. megaterium NBRC15308, B. megaterium FDU301 grew much better in the arid medium (15\% PEG200 (w/ w)) (Fig. 1b).

\section{Global overview of the RNA-Seq data}

The transcriptome of $B$. megaterium FDU301 in the growth phase $(4 \mathrm{~h})$ under control (LB medium, L) and the simulated arid condition (LB medium with 15\% PEG200, P) was analyzed with RNA-seq. The RNA-seq data have been submitted to NCBI SRA (accession numbers PRJNA649685). After filtration, a total of 51,893, 124 and 61,892,804 reads were obtained from $\mathrm{L}$ and $\mathrm{P}$ samples, respectively. For both samples, more than $95 \%$ of the reads were mapped to the B. megaterium FDU301 reference genome (Table 1$)$. In order to verify the transcriptomic results, ten differentially expressed genes (DEGs) were randomly selected and their transcriptional level were determined with quantitative reverse transcription PCR (RT-qPCR). The results of RNA-seq and RT-qPCR were generally consistent with each other, 

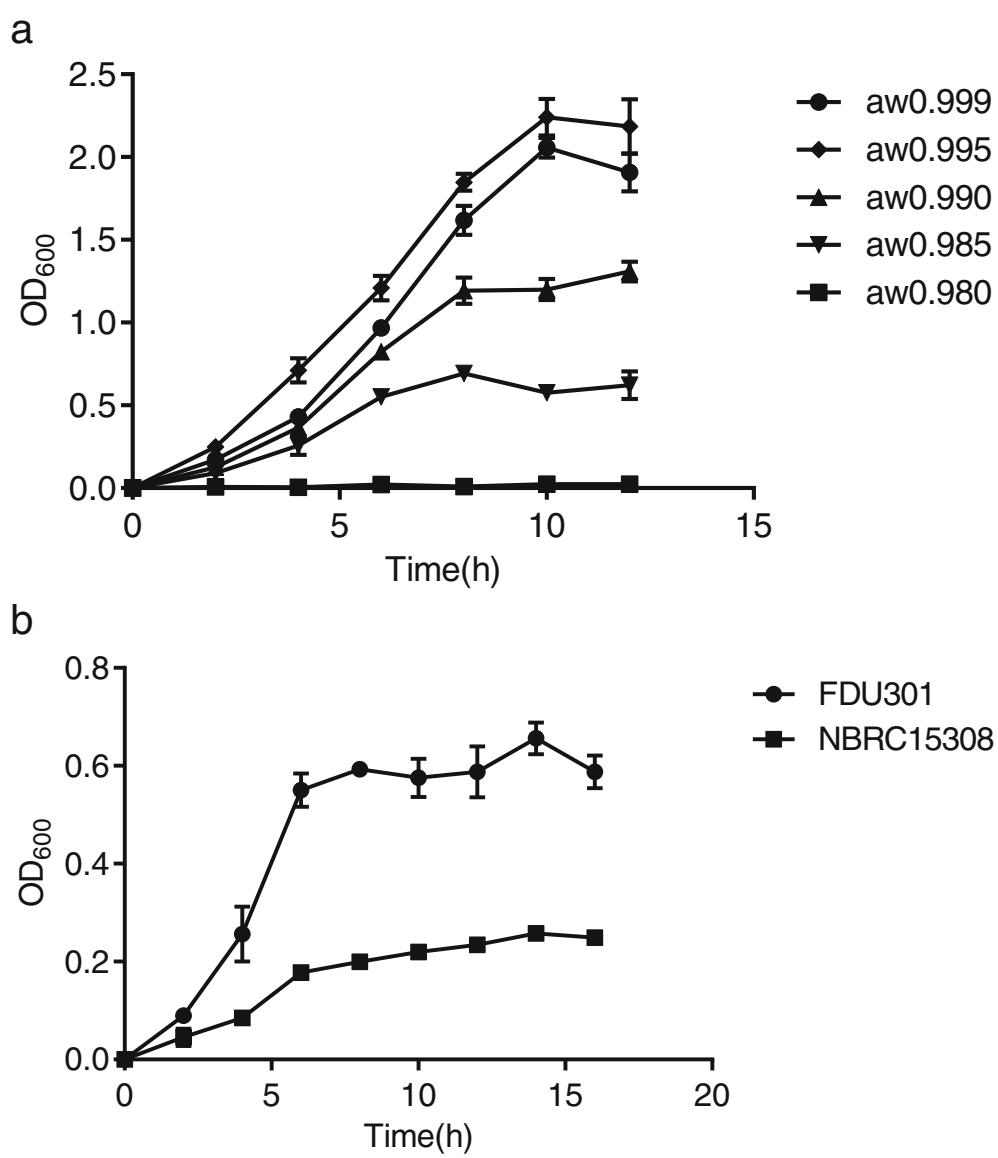

Fig. 1 Growth curves of B. megaterium FDU301 and B. megaterium NBRC15308. a: Grwoth of B. megaterium FDU301 in LB medium with different concentration of PEG200. b: Grwoth of B. megaterium FDU301 and B. megaterium NBRC15308 in LB medium with 15\% PEG200

indicating that the transcriptomic results reflected the differences in gene expression under the arid and normal conditions (Additional file 1: Figure S1).

As shown in Fig. 2a, the correlation between the three biological replicates of each sample ( $\mathrm{L}$ and $\mathrm{P}$ ) was high, indicating that the sequencing data was highly reproducible. Meanwhile the difference between treatment groups was obvious. Two groups were also well separated from the other in the principal component analysis (Fig. 2b). These showed that arid stress had a significant effect on the gene expression of FDU301.
The volcano map of DEGs is shown in Fig. 2c. Compared with the control group, the expression levels of 2941 genes were significantly different under the simulated arid conditions (FDR $<0.05 \&\left|\log _{2} \mathrm{FC}\right| \geq 1$ ), of which 1422 genes were upregulated and 1519 genes were downregulated (Additional file 2: Table S1).

\section{Annotation analysis of DEGs}

The 2941 DEGs (FDR $<0.05 \&\left|\log _{2} \mathrm{FC}\right| \geq 1$ ) were annotated with COG and KEGG databases. According to COG annotation, DEGs were seen in most of the COG

Table 1 Quality control statistics of transcriptomic data and genome mapping

\begin{tabular}{llllll}
\hline Sample name & Clean reads (bp) & Clean bases (bp) & Q30 (\%) & Genome mapped reads (bp) & Genome mapped ratio (\%) \\
\hline L_1 & $18,048,182$ & $2,440,791,296$ & 95.54 & $17,618,940$ & 97.62 \\
L_2 & $17,345,958$ & $2,344,077,298$ & 95.46 & $16,977,526$ & 97.88 \\
L_3 & $16,498,984$ & $2,197,149,343$ & 95.30 & $16,090,245$ & 97.52 \\
P_1 & $21,088,294$ & $2,798,604,312$ & 95.48 & $20,290,912$ & 96.22 \\
P_2 & $18,406,784$ & $2,415,364,313$ & 95.71 & $17,735,307$ & 96.35 \\
P_3 & $22,397,726$ & $2,886,319,033$ & 95.76 & $21,341,293$ & 95.28 \\
\hline
\end{tabular}




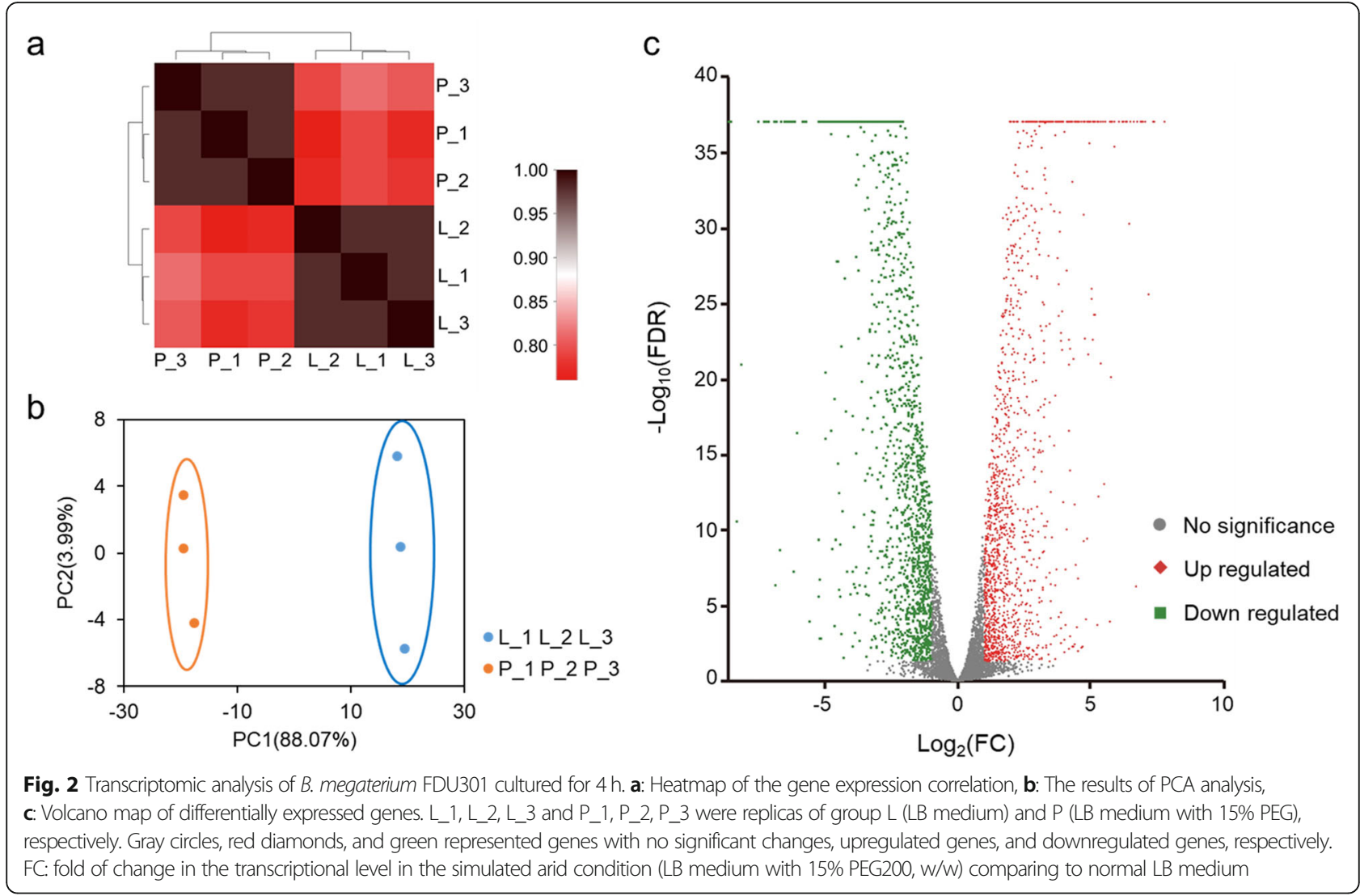

categories, which meant that the response of FDU301 to the arid stress was a complicated process (Additional file 3: Table S2). As shown in Fig. 3, the category with the highest proportion of upregulated genes was inorganic ion transport and metabolism (P, 41.56\%). In terms of downregulated genes, categories with more than $30 \%$ genes downregulated included carbohydrate transport and metabolism (G); translation, ribosomal structure and biogenesis (J); energy production and conversion (C); lipid transport and metabolism (I); and amino acid transport and metabolism (E). These results suggested FDU301 had general suppressions in metabolism and protein production, and enhancement in the transport for inorganic ion, such as $\mathrm{Fe}, \mathrm{Zn}, \mathrm{Ni}$, in face of the arid stress.

KEGG annotation showed that the arid stress induced a significant upregulation in the transcription of $\mathrm{ABC}$ transporters-associated genes (Additional file 4: Table S3), and a significant downregulation in that of oxidative phosphorylation and glycolysis-related genes (Additional file 5: Table S4).

\section{Major changes in gene expression under arid stress}

Selected genes with significant changes in transcription under the simulated arid (15\% PEG200 (w/w)) and normal conditions were further analyzed with RT-qPCR.

\section{Oxidative stress-responsive genes}

PerR is a key regulatory protein for oxidative stress response in Bacillus spp. [33]. As shown in Fig. 4a, perR was upregulated under arid condition. Several genes known to be regulated by perR were also upregulated significantly, including fur, dps, and katE (Fig. 4a). Fur encodes a major suppressor for the expression of many ferrous uptake operons, whereas $d p s$ and $k a t E$ are related to avoiding DNA damage and removing ROS, respectively. These results were consistent with the level ROS in FDU301 cells grown in the medium with different concentration of PEG200 (Additional file 6: Figure S2), suggesting that oxidative stress was one of the main challenges for the bacteria in the simulated arid condition.

\section{$\mathrm{Fe}^{2+}$ transportation genes}

Under oxidative stress, $\mathrm{Fe}^{2+}$ will react with $\mathrm{H}_{2} \mathrm{O}_{2}$ through fenton reaction to form hydroperoxide, which is highly active in destroying DNA. Upregulations of many $\mathrm{Fe}^{2+}$ transportation-related genes were seen in B. megaterium FDU301 under arid condition. In fact, Fur is a suppressor for $\mathrm{Fe}^{2+}$ uptake, and Dps functions by binding $\mathrm{Fe}^{2+}$ and reduces the level of free $\mathrm{Fe}^{2+}$ in the cell. Meanwhile, the $\mathrm{Fe}^{2+}$ uptake gene $f e o B$ [34], was also found to be greatly upregulated in arid condition (Fig. 4a), suggesting a delicate balance of $\mathrm{Fe}^{2+}$. 


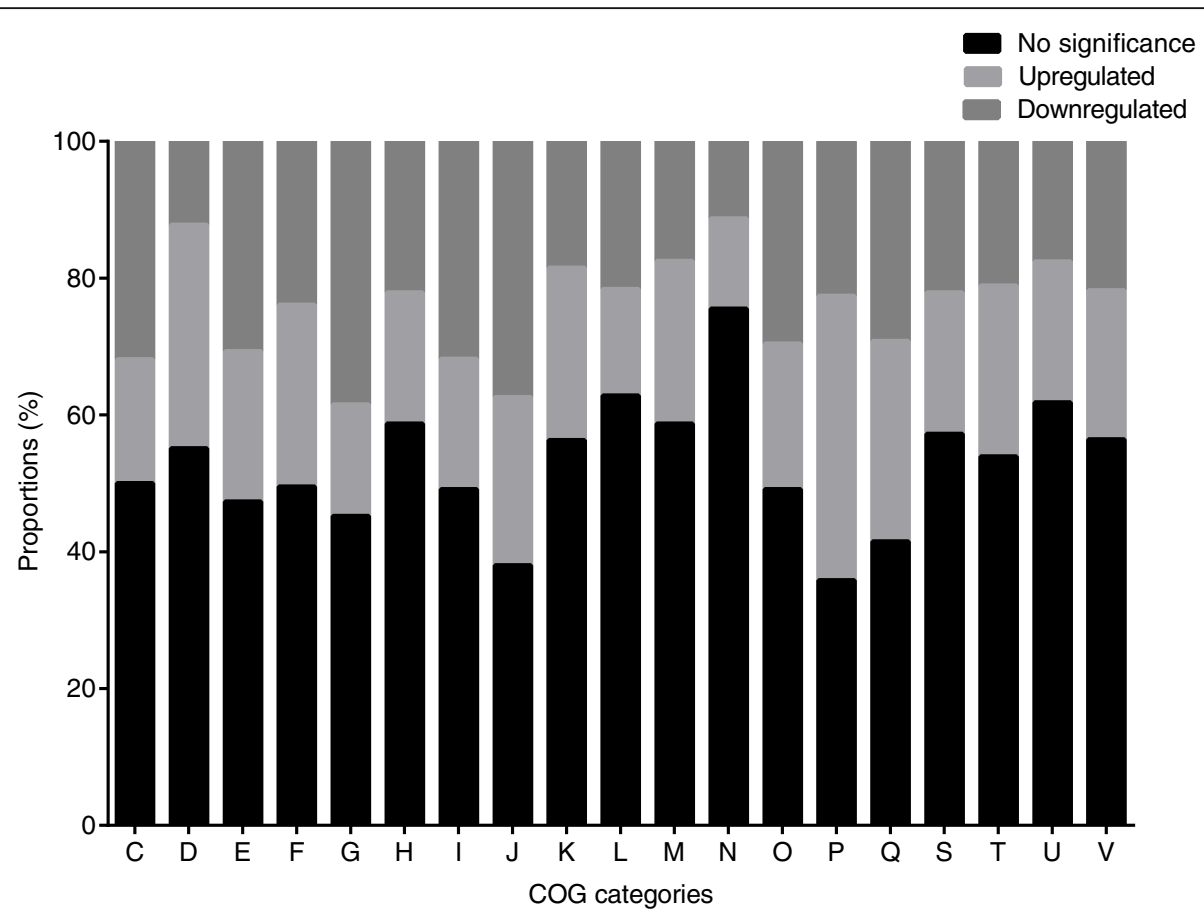

Fig. 3 COG analysis of DEGs of B. megaterium FDU301 under normal and arid conditions. Proportions of all genes annotated with COG database that were upregulated (light grey), downregulated (dark grey), and not-significantly-changed (black) under the simulated arid condition (LB medium with 15\% PEG200) comparing to normal condition (LB medium) were shown. C: energy production and conversion, D: cell cycle control, cell division, chromosome partitioning, E: amino acid transport and metabolism, F: nucleotide transport and metabolism, G: carbohydrate transport and metabolism, H: coenzyme transport and metabolism, I: lipid transport and metabolism, J: translation, ribosomal structure and biogenesis, $\mathrm{K}$ : transcription, L: replication, recombination and repair, M: cell wall/membrane/envelope biogenesis, N: cell motility, O: posttranslational modification, protein turnover, chaperones, P: inorganic ion transport and metabolism, Q: secondary metabolites biosynthesis, transport and catabolism, S: function unknown, T: signal transduction mechanisms, U: intracellular trafficking, secretion, and vesicular transport, V: defense mechanisms

\section{Ectoine biosynthesis genes}

The $e c t B$ and $e c t A$ were significantly upregulated by about 23.10-fold and 8.40-fold, respectively in arid condition (Fig. 4b). The two genes are involved in the biosynthesis of compatible solute ectoine [35]. Meanwhile, genes related to the transportation and biosynthesis of another commonly used compatible solute, glycinebetaine, were not significantly changed, or even downregulated (Table 2, Additional file 2: Table S1).

\section{Sporulation genes}

Under the simulated arid condition, genes related to sporulation stage II (spoIIB, spoIIE, spoIIGA) were upregulated by about 8.57 to 18.38 -fold. $S s p D$, the gene encoding small acid-soluble spore proteins (SASP), which is a major protective component of Bacillus spores, were also highly expressed (Fig. 4c).

\section{TipA gene}

TipA encodes a transcriptional regulator activated by cyclic thiopeptide antibiotics, such as thiostrepton, and promothiocin in Streptomyces [36]. Under the simulated arid condition, tipA was one of the most dramatically upregulated genes, in terms of the fold of change in the transcriptional level (Fig. 4d). TipA had not been noticed in previous studies on bacterial arid tolerance.

\section{Respiratory and glycolysis genes}

As shown in Fig. 4e, under the simulated arid condition, genes related to oxidative phosphorylation $(a t p B, a t p E$, $\operatorname{atp} F, \operatorname{atpH}, \operatorname{atp} A, \operatorname{atp} G, \operatorname{atpD}, \operatorname{atpC})$ were downregulated to various degrees. Meanwhile, some glycolysisrelated genes ( $p g k, t p i A, f r m A)$ were also downregulated (Fig. 4f). This might reflect the slow growing status of bacteria in the simulated arid condition.

\section{Changes in gene expression under 5\% PEG200}

As shown in Fig. 1a, FDU301 grew slightly faster in medium with 5\% PEG200 than in LB medium without PEG200. We compared the expression of selected genes with 0,5, and 15\% PEG200. Although genes upregulated in 15\% PEG200 were also upregulated in 5\% PEG200, the levels of upregulation for most of them were significantly lower than that in 15\% PEG200 (Fig. 5a and b). In contrast, genes downregulated in 15\% PEG200, including those in oxidative phosphorylation ( $a t p B$, atpE, atpF, $\operatorname{atpH}, \operatorname{atp} A, \operatorname{atp} G, \operatorname{atpD}, \operatorname{atpC})$ and glycolysis (pgk, tpiA, frmA) pathways, were instead slightly upregulated 


\section{a}

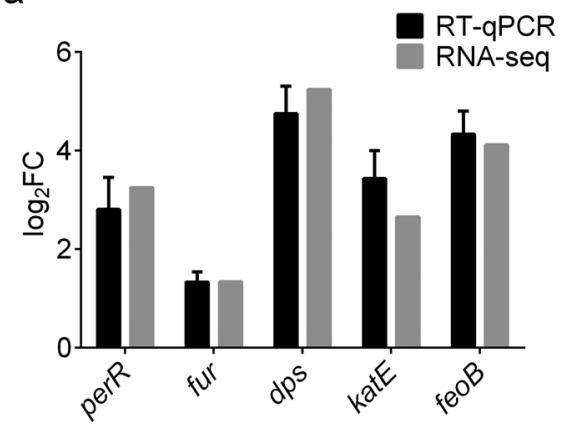

C

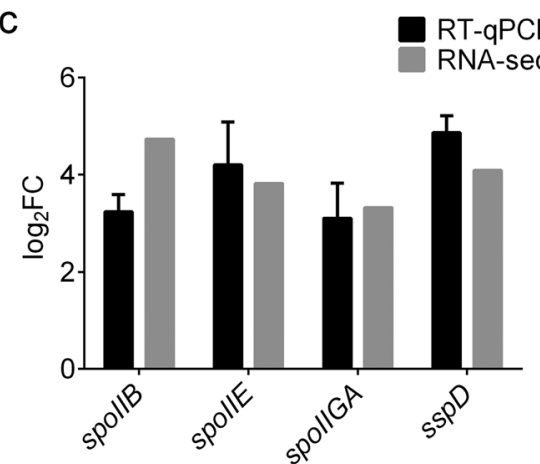

e

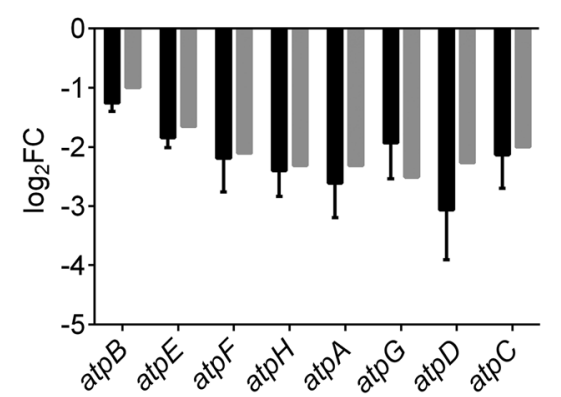

b

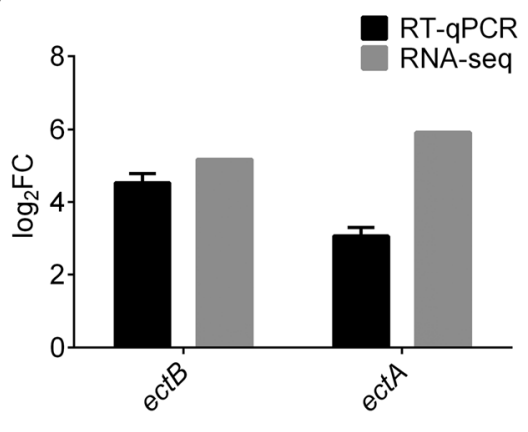

d
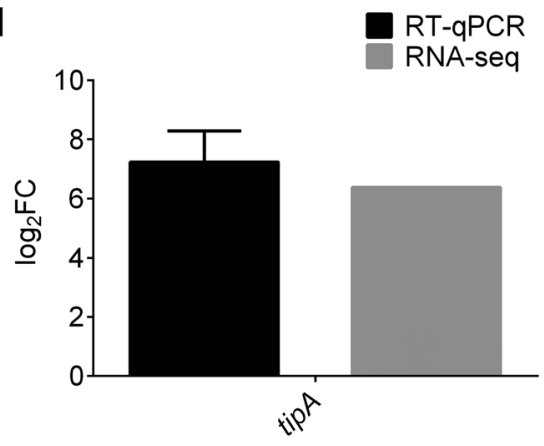

RT-qPCR

RNA-seq

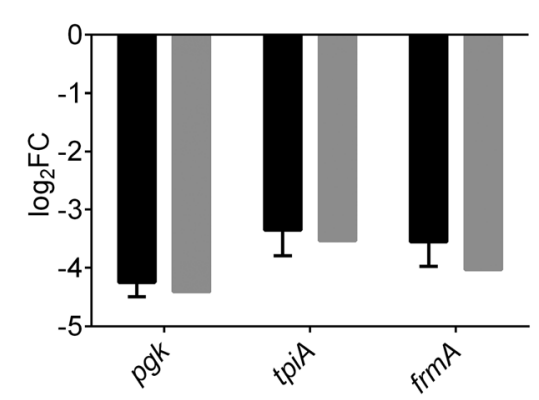

Fig. 4 Changes in the expression of genes of B. megaterium FDU301 under normal and arid conditions. The transcription levels of selected genes were determined by transcriptomic analysis and RT-qPCR. a: Oxidative stress-responsive genes and Fe ${ }^{2+}$ transportation-related genes, $\mathbf{b}$ : Ectoine biosynthesis-related genes, c: Sporulation-related genes, d: TipA, e: Oxidative phosphorylation-related genes, f: Glycolysis-related genes. FC: fold of change in the transcriptional level in the simulated arid condition (LB medium with 15\% PEG200, w/w) comparing to normal LB medium

Table 2 Changes of expression of proVWX operons under normal and arid conditions (RNA-seq)

\begin{tabular}{|c|c|c|c|c|}
\hline Gene ID & Gene name & Description & $\log _{2} \mathrm{FC}$ & FDR \\
\hline FDZ14_RS20255 & prox & glycine/betaine $\mathrm{ABC}$ transporter & -0.76 & 0.18 \\
\hline FDZ14_RS20265 & prov & glycine/betaine ABC transporter ATP-binding protein & 0.70 & 0.05 \\
\hline FDZ14_RS20260 & prow & glycine/betaine $A B C$ transporter & 0.99 & 0.08 \\
\hline FDZ14_RS23515 & proX & glycine/betaine $\mathrm{ABC}$ transporter & -0.92 & 0.00 \\
\hline FDZ14_RS23520 & prov & glycine/betaine ABC transporter ATP-binding protein & 0.42 & 0.07 \\
\hline FDZ14_RS23525 & prow & glycine/betaine $A B C$ transporter & 0.74 & 0.00 \\
\hline
\end{tabular}


a

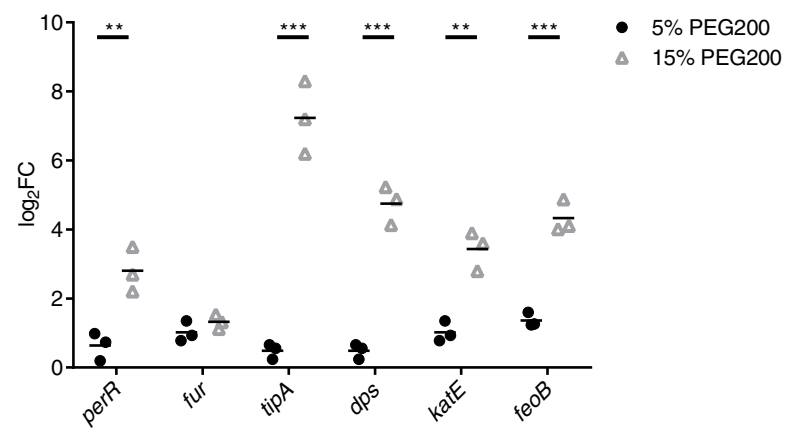

C

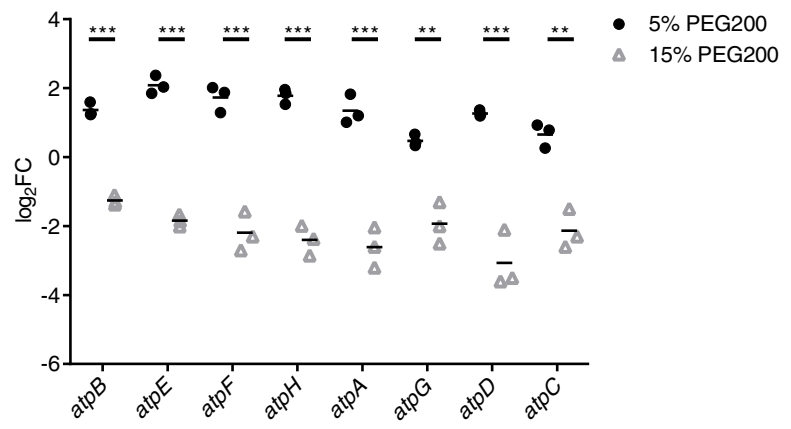

b

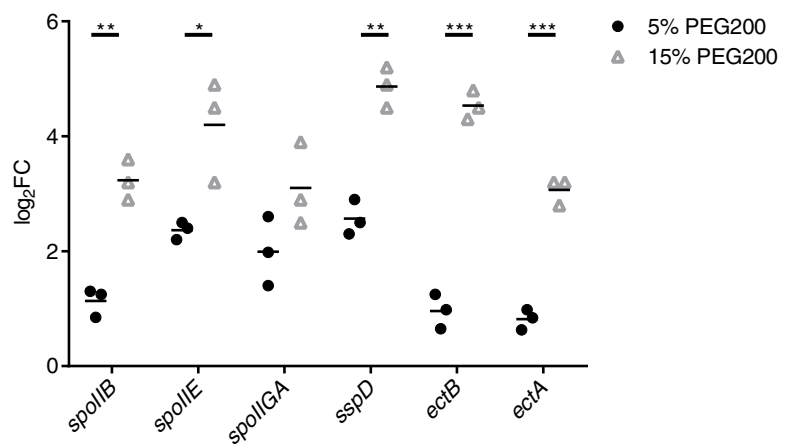

d

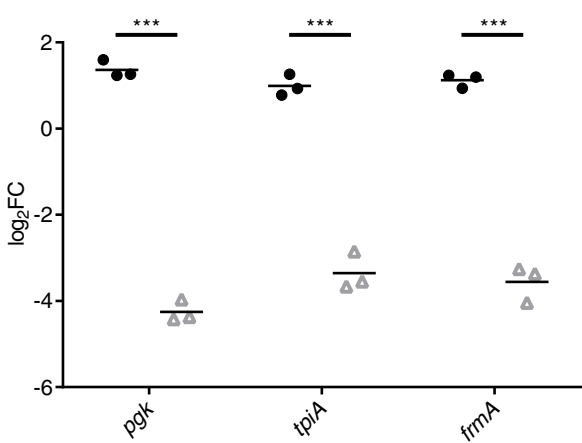

- $5 \%$ PEG200

$\triangle 15 \%$ PEG200

Fig. 5 Changes in the expression of genes of B. megaterium FDU301 under different concentration of PEG200. The transcription levels of selected genes were determined by RT-qPCR. $\mathbf{a}$ : Oxidative stress-responsive genes, tipA and Fe ${ }^{2+}$ transportation-related genes, $\mathbf{b}$ : Genes related to ectoine biosynthesis and sporulation, c: Oxidative phosphorylation-related genes, $\mathbf{d}$ : Glycolysis-related genes. FC: fold of change in the transcriptional level in LB medium with $5 \%$ or $15 \%$ PEG200 comparing to normal LB medium. $*: p<0.05,{ }^{* *}: p<0.01,{ }^{* * *}: p<0.001$

(Fig. 5c and d). It seemed that under 5\% PEG200, the bacteria sensed the change and increased their metabolisms to be prepared for worsen environments.

\section{Discussion}

Most studies on the microorganisms of paper surfaces have focused on fungi $[37,38]$, which is generally more resistant to water deficiency and more harmful to paper than bacteria. However, the role of bacteria and their mechanisms to adapt to the environment also need to be explored, since recent high-throughput sequencing studies have proven the presence of hundreds of bacteria species, or their remains, on paper surfaces $[39,40]$.

In most water activity-related studies, sodium chloride or glycerol was used to adjust water activity in the culture medium. However, apart from affecting water activity, sodium chloride also changes osmotic pressure, whereas glycerol can be utilized by some microbes as a stress protectant [41]. At the same time, high molecular weight PEG (PEG6000) is used as an arid mimic in research on rhizosphere microbes [42]. We found that PEG200 reduced water activity of the medium effectively, while the PEG2000 and PEG6000 had limited effect on water activity. In addition, PEG200 was not used as carbon source by FDU301, as the concentration of PEG200 in the medium remain unchanged after culturing for $4 \mathrm{~h}$ (data not shown). Using PEG200 as the arid simulator, B. megaterium FDU301 was isolated from plaque areas on the paper in an old book.

Transcriptional analysis of $B$. megaterium FDU301 revealed that genes in multiple metabolic pathways responded to the arid environment simulated with 15\% PEG200. For example, FDU301 utilized compatible solutes to resist the arid condition. Microorganisms often use a variety of compatible solutes to deal with hypertonic conditions, such as proline, ectoine, and glycinebetaine [43]. We found that the transcription of ectoine biosynthesis-related genes, ectB and ectA, were greatly enhanced under arid condition. Meanwhile, the expression of two sets of proVWXX operons related to glycinebetaine/proline transport was not significantly upregulated, or even downregulated (Table 2). These were different from many other bacteria [3], indicating that B.megaterium FDU301 might use ectoine, rather than glycine-betaine and proline, as the major compatible solute. It is reported that different Bacillus spp. used different compatible solute 
under osmotic stress [44]. The expression and transportation of other potential compatible solutes, such as spermidine and putrescine, were also increased (Additional file 2: Table S1).

Forming spores is a common strategy of bacteria in Bacillus to sustain in unfavorable environments. Genes related to sporulation stage II (spoIIB, spoIIE, spoIIGA), and SASP-encoding gene $S s p D$ were upregulated in the simulated arid conditions. The sporulation of $B$. subtilis can be divided into 6 stages, and each stage requires the co-regulation of multiple genes [45]. The sporulation stage II genes (spoIIB, spoIIE, spoIIGA) are controlled by a series of compartment-specific $\sigma$ factors and responsible for the asymmetric septation [43]. Small, acid-soluble proteins (SASP) is related to the formation and maturation of spores [46]. However, the expression of genes related to further stages in sporulation were not changed significantly of even downregulated (Additional file 2: Table S1). This was consistent with our observation that there was no significant difference in the rate of sporulation of FDU301 in medium with 0, 5, 15\% PEG200 after $4 \mathrm{~h}$ cultivation (data not show).

On the other side, genes in oxidative phosphorylation pathway (atpB, atpE, atpF, atpH, atpA, atpG, atpD, $a t p C)$, as well as genes related to glycolysis ( $p g k$, tpiA, $\operatorname{frm} A$ ) were downregulated significantly in the simulated arid condition (Additional file 5: Table S4). This might reflect the suppression of general metabolism in response to stress, and was consistent with the decrease in the transcription of many ribosome proteins under the arid condition (Additional file 2: Table S1).

Meanwhile, we found that oxidative stress was the major challenge that $B$. megaterium FDU301 faced in PEG200-mediated arid condition. Significant upregulation of perR, a regulator of the peroxidative stress response, was seen. In Bacillus spp., PerR is a $\mathrm{Fe}^{2+}$ containing DNA binding protein that represses the expression of a series of genes [47]. In the presence of $\mathrm{H}_{2} \mathrm{O}_{2}$, perR will lose its DNA binding activity, resulting in the expression of many oxidative stress-responsive genes, including itself, another transcription regulator, fur, as well as dps, katE, and several other related genes [33, 48]. In consistent with that, the transcription of fur, $d p s$, and katE was found to be significantly increased in the simulated arid condition. Dps and katE encodes DNA protection protein and catalase, respectively. The fact that adding reductive agents (glutathione or ascorbic acid) to the medium, alleviated the effect of arid stress (data not show), further supported that oxidative stress was the key factor in limiting the growth of FDU301 in the simulated arid condition.

In Bacillus spp., fur encodes a protein that regulated cellular iron uptake and iron carrier biosynthesis [49]. In the oxidative condition, $\mathrm{Fe}^{2+}$ is highly deleterious to
DNA. Meanwhile, $\mathrm{Fe}^{2+}$ is also essential for perR-mediated sensing of oxidative stress. PerR, fur and $d p s$ are all $\mathrm{Fe}^{2+}$-containing protein. Activation of Fur protein usually results in the inhibition of $\mathrm{Fe}^{2+}$ uptake. However, we also saw the increased expression of $f e o B$, a gene responsible for $\mathrm{Fe}^{2+}$ uptake, in the simulated arid condition, suggesting that the concentration of $\mathrm{Fe}^{2+}$ was relatively low in cells under such condition. It seems that a delicate balance of $\mathrm{Fe}^{2+}$ is very important for the bacteria to survive in such a stressful condition.

Among DEGs, the expression of transcriptional regulatory factor tipA increased dramatically (up to 150.12fold) compared with the control group. In Streptomyces spp., tipA belongs to the MerR transcriptional regulatory family and is induced by thiostrepton to produce two regulatory proteins, TipAL and TipAS [50, 51]. Many other genes in the MerR family have been shown to be involved in the regulation of bacteria on a range of stresses, including oxidative stress and metal ions [52]. It is speculated that tipA played an important role in the regulation of stress adaptation to arid condition for $B$. megaterium FDU301, though the exact mechanism needs to be further explored.

Interestingly, the transcription of tipA was only moderately upregulated, or even downregulated, in the arid stress mediated by sodium chloride or glycerol, respectively (Additional file 7: Figure S3). Apart from tipA, it was also noted that in the arid condition mediated by sodium chloride or glycerol, genes related to oxidative phosphorylation and glycolysis were usually upregulated [53-55], unlike the results we observed in B. megaterium FDU301 using 15\% PEG200. These results suggested that the arid environment simulated by PEG200 was in some way different from that using salt or glycerol, and the bacterial adaptation to them may also be different.

\section{Conclusions}

A strain of B. megaterium, FDU301, was isolated from a paper surface and its transcriptional adaptation to the arid condition, simulated with 15\% PEG200, was studied. The arid condition caused oxidative stress for FDU301, and the aerobic respiration was inhibited. FDU301 mitigated the oxidative stress by enhancing the expression of genes related to anti-oxidation, iron ion transporters, and transcriptional regulatory factors. The expression of the transcriptional regulator tipA increased significantly. Under the simulated arid conditions, FDU301 increased the biosynthesis of compatible solutes, such as ectoine, spermidine and putrescine, and started the process of sporulation. In low concentration of PEG200 (5\%), most of these upregulated genes were also upregulated, but to significantly lower level than that in 15\% PEG200 medium, whereas the downregulated genes in oxidative phosphorylation and glycolysis pathways were 
upregulated significantly, suggesting a preparation for the adverse condition. To our knowledge, this is the first study using RNA-seq to analyze the adaption of $B$. megaterium to arid environments.

\section{Methods}

Isolation and growth of bacteria strain

A sterile polyester fiber swab was wetted with $20 \mu \mathrm{l}$ wetting solution $(0.15 \mathrm{M}$ sodium chloride+ $0.1 \%$ Tween 80$)$, and used to wipe gently on colored plaques of a leaflet from an old book. The swab head was then carefully peeled off with sterile tweezers and transferred into 50 $\mathrm{ml} \mathrm{LB}$ liquid medium. The sample was agitated at $37^{\circ} \mathrm{C}$, $200 \mathrm{rpm}$ overnight, before the suspension was spread on LB agar medium with PEG200 (10\% w/w). A total of seventeen bacterial colonies were obtained. Then they were transferred to medium with PEG200 (15\% w/w), with only one colony survived. To exam its tolerance to PEG200-mediated arid condition, the bacteria was precultured in LB liquid medium at $37^{\circ} \mathrm{C}, 200 \mathrm{rpm}$, for about $8 \mathrm{~h}$, before being transferred to LB liquid medium with different concentrations of PEG200 (5-20\% w/w), at an inoculation ratio of $5 \%$. The bacteria were further cultured at $37^{\circ} \mathrm{C}$ and $200 \mathrm{rpm}$. B. megaterium NBRC15308 was obtained from Forte Cheung Biological Technology (Shanghai, China).

\section{Extraction of total RNA and RT-qPCR analysis}

The total RNA was extracted from bacteria under normal and the simulated arid conditions (15\% PEG200 ( $w /$ w)) with the improved Trizol (Takara) method [56]. The RNA was reverse-transcribed into cDNA using the PrimeScript ${ }^{\mathrm{RT}}$ reagent Kit with gDNA Eraser (Takara). The cDNA was used as template in RT-qPCR with SYBR qPCR Master Mix (Takara), with gyrB as the endogenous control. All reactions were carried out in triplicate. The relative quantitative algorithm $\left(2^{-\triangle \Delta C T}\right)$ was adopted to calculate the transcription levels of DEGs in different treatments [57]. The primers used in the experiment were displayed in Additional file 8 (Table S5).

\section{Analysis of transcriptomic data}

Total RNAs from B. megaterium FDU301 of exponential growth phase $(4 \mathrm{~h})$ in arid medium $(15 \%$ PEG200 (w/w)) or normal medium, were used for RNA-Seq library construction and sequencing (Illumina Hiseq2000 platform, Meiji Biotechnology) [58]. To obtain clean reads, the adapter sequences and low quality bases (the sequencing quality value, $\mathrm{Q}$, less than 20) were removed from the raw sequence [58], and the clean reads were aligned with the B. megaterium FDU301 genome using Bowtie2 software [59].

The transcriptional profiles of B. megaterium FDU301 under normal (L) and arid conditions with 15\% PEG200 $(\mathrm{w} / \mathrm{w})(\mathrm{P})$ after $4 \mathrm{~h}$ of cultivation were compared. Gene expression was quantitatively analyzed via TPM (transcripts per million reads) algorithm [60]. Genes with a fold of change in expression equal or greater than 2 $\left(\left|\log _{2} \mathrm{FC}\right| \geq 1\right)$ and adjusted $P$-value (FDR) less than 0.05 $($ FDR $<0.05)$ were identified by DESeq2 software [61] and specified as differently expressed. The experiment was carried out in triplicate. Functional annotation was done using the COG [62] and KEGG databases [63]. edgeR software were used to draw the volcano map of gene expression differences [64].

\section{Statistical analysis}

Data from triplicate or more parallel experiments were used to calculate means and standard deviations. Statistical significance between groups was evaluated using student's t test.

\section{Supplementary Information}

The online version contains supplementary material available at https://doi. org/10.1186/s12866-020-02039-4

Additional file 1: Figure S1. RT-qPCR verification. Ten DEGs were randomly selected and their transcriptional level were determined with RTqPCR. FC: fold of change in the transcriptional level in simulated arid condition (LB medium with 15\% PEG200, w/w) comparing to normal LB medium.

Additional file 2: Table S1. Significant DEGs.

Additional file 3: Table S2. COG annotation.

Additional file 4: Table S3. $A B C$ transporters-related genes.

Additional file 5: Table S4. Respiration-related genes.

Additional file 6: Figure S2. Effect of different arid conditions on the level of ROS in the cell of B. megaterium FDU301. The Bacterial ROS HiFluo Assay Kit (Chundubio, China) was used to determine the oxidative stress of FDU301 under different concentrations of PEG200 (0-15\% (W) w)).

Additional file 7: Figure S3. Effect of different water activity regulators on the expression of tipA gene. The expression of tipA gene in $B$. megaterium FDU301 grown in LB medium of aw 0.985, using PEG200, sodium chloride and glycerol to adjust the water activity, respectively, were determined by real-time RT-qPCR. FC: fold of change in the transcriptional level in arid condition medium comparing to normal LB medium.

Additional file 8: Table S5. Primers used in this study.

\section{Abbreviations}

PEG200: polyethylene glycol 200; DEGs: differentially expressed genes; TPM: transcripts per million reads; FDR: false discovery rate; ROS: reactive oxygen species; SASP: small acid-soluble spore proteins

\section{Acknowledgements}

We thank Professor Zhexue Quan and Mr. Bin Zou for helps in highthroughput data analysis. Ruyi Zhang is acknowledged for his assistance in uploading NCBI data.

Authors' contributions

$J Z, L Z, J Y$ contributed proposing and optimizing the experimental design of this study. $L Z, Y Z, J L, Y X, W W$ and $X L$ performed the experiments. $L Z$ and $J Z$ wrote the manuscript. All authors have read and approved the manuscript. 


\section{Funding}

This work was financially supported by National Key R\&D Program of China (2019YFC1520400). The Funding body had no role in the design of the study, the collection, analysis, and interpretation of data, or in writing the manuscript.

\section{Availability of data and materials}

The datasets generated during the current study are available in NCBI GenBank (accession numbers CP045267-CP045276) and NCBI SRA (accession numbers PRJNA649685).

\section{Ethics approval and consent to participate}

Not applicable.

\section{Consent for publication}

Not applicable.

\section{Competing interests}

The authors declare that they have no competing interests.

Received: 11 August 2020 Accepted: 8 November 2020

Published online: 16 November 2020

\section{References}

1. Diruggiero J, Wierzchos J, Robinson C, Souterre T, Ravel J, Artieda O, et al. Microbial colonisation of chasmoendolithic habitats in the hyper-arid zone of the Atacama Desert. Biogeosciences. 2013;10:2439-50.

2. Finn S, Condell O, McClure P, Amézquita A, Fanning S. Mechanisms of survival, responses and sources of Salmonella in low-moisture environments. Front Microbiol. 2013;4:331.

3. Liu X, Luo Y, Mohamed OA, Liu D, Wei G. Global transcriptome analysis of Mesorhizobium alhagi CCNWXJ12-2 under salt stress. BMC Microbiol. 2014; 14:319.

4. Grant WD. Life at low water activity. Philos Trans R Soc Lond Ser B Biol Sci. 2004;359(1448):1249-67.

5. Stevenson A, Hamill PG, O'Kane CJ, Kminek G, Rummel JD, Voytek MA, et al. Aspergillus penicillioides differentiation and cell division at 0.585 water activity. Environ Microbiol. 2017;19(2):687-97.

6. Lievens B, Hallsworth JE, Pozo MI, Belgacem ZB, Stevenson A, Willems KA, et al. Microbiology of sugar-rich environments: diversity, ecology and system constraints. Environ Microbiol. 2015;17(2):278-98.

7. Stevenson A, Cray JA, Williams JP, Santos R, Sahay R, Neuenkirchen N, et al. Is there a common water-activity limit for the three domains of life? ISME J. 2015:9(6):1333-51.

8. Stevenson A, Burkhardt J, Cockell CS, Cray JA, Dijksterhuis J, Fox-Powell M, et al. Multiplication of microbes below 0.690 water activity: implications for terrestrial and extraterrestrial life. Environ Microbiol. 2015;17(2):257-77.

9. Nazareth S, Gonsalves V. Aspergillus penicillioides - a true halophile existing in hypersaline and polyhaline econiches. Ann Microbiol. 2014;64(1):397-402.

10. de Lima AF, Stevenson A, Baxter E, Gillion JLM, Hejazi F, Hayes S, et al. Concomitant osmotic and chaotropicity-induced stresses in Aspergillus wentii: compatible solutes determine the biotic window. Curr Genet. 2015; 61(3):457-77.

11. Mattenberger F, Sabater-Muñoz B, Hallsworth JE, Fares MA. Glycerol stress in Saccharomyces cerevisiae: cellular responses and evolved adaptations. Environ Microbiol. 2017;19(3):990-1007.

12. Leong S-IL, Lantz H, Pettersson OV, Frisvad JC, Thrane U, Heipieper HJ, et al. Genome and physiology of the ascomycete filamentous fungus Xeromyces bisporus, the most xerophilic organism isolated to date. Environ Microbiol. 2015;17(2):496-513.

13. Maserati A, Fink RC, Lourenco A, Julius ML, Diez-Gonzalez F. General response of Salmonella enterica serovar typhimurium to desiccation: a new role for the virulence factors sopD and sseD in survival. PLoS One. 2017; 12(11):e0187692

14. Walsh RL, Camilli A. Streptococcus pneumoniae is desiccation tolerant and infectious upon rehydration. mBio. 2011;2(3):e00092-11.

15. Roberson EB, Firestone MK. Relationship between desiccation and exopolysaccharide production in a soil Pseudomonas sp. Appl Environ Microbiol. 1992;58(4):1284-91.

16. Breedveld MW, Miller KJ. Cyclic beta-glucans of members of the family Rhizobiaceae. Microbiol Rev. 1994;58(2):145-61.
17. Csonka LN, Hanson AD. Prokaryotic osmoregulation: genetics and physiology. Annu Rev Microbiol. 1991;45(1):569-606.

18. Ruhal R, Kataria R, Choudhury B. Trends in bacterial trehalose metabolism and significant nodes of metabolic pathway in the direction of trehalose accumulation. Microb Biotechnol. 2013;6(5):493-502.

19. Li H, Bhaskara A, Megalis C, Tortorello ML. Transcriptomic analysis of Salmonella desiccation resistance. Foodborne Pathog Dis. 2012;9(12): 1143-51.

20. Finn S, Händler K, Condell O, Colgan A, Cooney S, McClure P, et al. ProP is required for the survival of desiccated Salmonella enterica serovar typhimurium cells on a stainless steel surface. Appl Environ Microbiol. 2013; 79(14):4376-84.

21. Balaji B, Connor K, Lucas JR, Anderson JM, Csonka LN. Timing of induction of osmotically controlled genes in Salmonella enterica serovar typhimurium, determined with quantitative real-time reverse transcription-PCR. Appl Environ Microbiol. 2005;71(12):8273-83.

22. Yuvaniyama P, Agar JN, Cash VL, Johnson MK, Dean DR. NifS-directed assembly of a transient [2Fe-2S] cluster within the NifU protein. Proc Natl Acad Sci U S A. 2000;97(2):599-604.

23. Zheng L, White $\mathrm{RH}$, Cash VL, Dean DR. Mechanism for the desulfurization of L-cysteine catalyzed by the nifS gene product. Biochemistry. 1994;33(15): 4714-20.

24. Krebs C, Agar JN, Smith AD, Frazzon J, Dean DR, Huynh BH, et al. IscA, an alternate scaffold for Fe-S cluster biosynthesis. Biochemistry. 2001;40(46): 14069-80.

25. Saini A, Mapolelo DT, Chahal HK, Johnson MK, Outten FW. SufD and SufC ATPase activity are required for iron acquisition during in vivo Fe-S cluster formation on SufB. Biochemistry. 2010;49(43):9402-12.

26. García A. Anhydrobiosis in bacteria: from physiology to applications. Biosci J. 2011:36:939-50.

27. Fredrickson JK, Li S-mW, Gaidamakova EK, Matrosova VY, Zhai M, Sulloway HM, et al. Protein oxidation: key to bacterial desiccation resistance? ISME J. 2008;2(4):393-403

28. Chaibenjawong P, Foster SJ. Desiccation tolerance in Staphylococcus aureus. Arch Microbiol. 2011;193(2):125-35.

29. Xu Z, Xie J, Liu J, Ji L, Soteyome T, Peters BM, et al. Whole-genome resequencing of Bacillus cereus and expression of genes functioning in sodium chloride stress. Microb Pathog. 2017:104:248-53.

30. Ninni L, Camargo MS, Meirelles AJA. Water activity in poly (ethylene glycol) aqueous solutions. Thermochim Acta. 1999;328(1):169-76.

31. Xiang $Y$, Wang $Y$, Shen $H$, Wang $D$. The draft genome sequence of Pseudomonas putida strain TGRB4, an aerobic bacterium capable of producing methylmercury. Curr Microbiol. 2020;77(4):522-7.

32. Koch $H$, Lücker $S$, Albertsen $M$, Kitzinger $K$, Herbold $C$, Spieck E, et al. Expanded metabolic versatility of ubiquitous nitrite-oxidizing bacteria from the genus Nitrospira. Proc Natl Acad Sci U S A. 2015;112(36):11371-6.

33. Faulkner MJ, Helmann JD. Peroxide stress elicits adaptive changes in bacterial metal ion homeostasis. Antioxid Redox Signal. 2011;15(1):175-89.

34. Lau CKY, Krewulak KD, Vogel HJ. Bacterial ferrous iron transport: the Feo system. FEMS Microbiol Rev. 2015;40(2):273-98.

35. Ofer N, Wishkautzan M, Meijler M, Wang Y, Speer A, Niederweis M, et al. Ectoine biosynthesis in Mycobacterium smegmatis. Appl Environ Microbiol. 2012:78(20):7483-6.

36. Kahmann JD, Sass H-J, Allan MG, Seto H, Thompson CJ, Grzesiek S. Structural basis for antibiotic recognition by the TipA class of multidrugresistance transcriptional regulators. EMBO J. 2003;22(8):1824-34.

37. Zyska B. Fungi isolated from library materials: a review of the literature. Int Biodeterior Biodegradation. 1997;40(1):43-51.

38. Arai H. Foxing caused by Fungi: twenty-five years of study. Int Biodeterior Biodegradation. 2000;46(3):181-8

39. Migliore L, Thaller MC, Vendittozzi G, Mejia AY, Mercuri F, Orlanducci S, et al. Purple spot damage dynamics investigated by an integrated approach on a 1244 A.D. parchment roll from the Secret Vatican Archive. Sci Rep. 2017;7(1): 9521.

40. Migliore L, Perini N, Mercuri F, Orlanducci S, Rubechini A, Thaller MC. Three ancient documents solve the jigsaw of the parchment purple spot deterioration and validate the microbial succession model. Sci Rep. 2019; 9(1):1623.

41. Bhaganna P, Bielecka A, Molinari G, Hallsworth J. Protective role of glycerol against benzene stress: insights from the Pseudomonas putida proteome. Curr Genet. 2015;62:419-29. 
42. Vardharajula S, Zulfikar Ali S, Grover M, Reddy G, Bandi V. Drought-tolerant plant growth promoting Bacillus spp.: effect on growth, osmolytes, and antioxidant status of maize under drought stress. J Plant Interact. 2011;6(1):1-14.

43. Gouffi K, Blanco C. Is the accumulation of osmoprotectant the unique mechanism involved in bacterial osmoprotection? Int J Food Microbiol. 2000;55(1):171-4.

44. KuhImann AU, Bremer E. Osmotically regulated synthesis of the compatible solute ectoine in Bacillus pasteurii and related Bacillus spp. Appl Environ Microbiol. 2002;68(2):772-83.

45. Tan IS, Ramamurthi KS. Spore formation in Bacillus subtilis. Environ Microbiol Rep. 2014;6(3):212-25.

46. Mason JM, Hackett RH, Setlow P. Regulation of expression of genes coding for small, acid-soluble proteins of Bacillus subtilis spores: studies using lacZ gene fusions. J Bacteriol. 1988;170(1):239-44.

47. Herbig AF, Helmann JD. Roles of metal ions and hydrogen peroxide in modulating the interaction of the Bacillus subtilis PerR peroxide regulon repressor with operator DNA. Mol Microbiol. 2001;41(4):849-59.

48. Mongkolsuk S, Helmann JD. Regulation of inducible peroxide stress responses. Mol Microbiol. 2002;45(1):9-15.

49. Bsat N, Herbig A, Casillas-Martinez L, Setlow P, Helmann JD. Bacillus subtilis contains multiple Fur homologues: identification of the iron uptake (Fur) and peroxide regulon (PerR) repressors. Mol Microbiol. 1998;29(1):189-98.

50. Holmes D, Caso J, Thompson C. Autogenous transcriptional activation of a thiostrepton-induced gene in Streptomyces lividans. EMBO J. 1993; 12:3183-91.

51. Chiu ML, Folcher M, Katoh T, Puglia AM, Vohradsky J, Yun B, et al. Broad spectrum thiopeptide recognition specificity of the Streptomyces lividans TipAL protein and its role in regulating gene expression. J Biol Chem. 1999; 274(29):20578-86.

52. Chiu ML, Folcher M, Griffin PR, Holt T, Klatt T, Thompson CJ. Characterization of the covalent binding of thiostrepton to a thiostrepton-induced protein from Streptomyces lividans. Biochemistry. 1996;35(7):2332-41.

53. Gruzdev N, McClelland M, Porwollik S, Ofaim S, Pinto R, Saldinger-Sela S. Global transcriptional analysis of dehydrated Salmonella enterica serovar typhimurium. Appl Environ Microbiol. 2012;78(22):7866-75.

54. Kocharunchitt C, King T, Gobius K, Bowman JP, Ross T. Integrated transcriptomic and proteomic analysis of the physiological response of Escherichia coli 0157:H7 Sakai to steady-state conditions of cold and water activity stress. Mol Cell Proteomics. 2012;11(1):M111.009019.

55. Riedel K, Lehner A. Identification of proteins involved in osmotic stress response in Enterobacter sakazakii by proteomics. Proteomics. 2007;7(8): 1217-31.

56. Villa-Rodríguez E, Ibarra-Gámez C, de los Santos-Villalobos S. Extraction of high-quality RNA from Bacillus subtilis with a lysozyme pre-treatment followed by the Trizol method. J Microbiol Methods. 2018;147:14-6.

57. Livak KJ, Schmittgen TD. Analysis of relative gene expression data using real-time quantitative PCR and the $2-\Delta \Delta C T$ method. Methods. 2001;25(4): 402-8.

58. Qin J, Wang X, Wang L, Zhu B, Zhang X, Yao Q, et al. Comparative transcriptome analysis reveals different molecular mechanisms of Bacillus coagulans 2-6 response to sodium lactate and calcium lactate during lactic acid production. PLoS One. 2015;10(4):e0124316.

59. Langmead B, Salzberg SL. Fast gapped-read alignment with bowtie 2. Nat Methods. 2012;9(4):357-9.

60. Li B, Ruotti V, Stewart RM, Thomson JA, Dewey CN. RNA-Seq gene expression estimation with read mapping uncertainty. Bioinformatics. 2010; 26(4):493-500.

61. Yao JQ, Yu F. DEB: a web interface for RNA-seq digital gene expression analysis. Bioinformation. 2011;7(1):44-5.

62. Jensen $L$, Julien $P$, Kuhn $M$, von Mering C, Muller J, Doerks T, et al. eggNOG: automated construction and annotation of orthologous groups of genes. Nucleic Acids Res. 2008;36(Database issue):D250-4.

63. Kanehisa M, Goto S. KEGG: Kyoto encyclopedia of genes and genomes. Nucleic Acids Res. 2000;28(1):27-30.

64. Chen Y, Lun AT, Smyth GK. Differential expression analysis of complex RNAseq experiments using edgeR. In: Datta S, Nettleton D, editors. Statistical analysis of next generation sequencing data; 2014. p. 51-74.

\section{Publisher's Note}

Springer Nature remains neutral with regard to jurisdictional claims in published maps and institutional affiliations.

Ready to submit your research? Choose BMC and benefit from:

- fast, convenient online submission

- thorough peer review by experienced researchers in your field

- rapid publication on acceptance

- support for research data, including large and complex data types

- gold Open Access which fosters wider collaboration and increased citations

- maximum visibility for your research: over $100 \mathrm{M}$ website views per year

At $\mathrm{BMC}$, research is always in progress.

Learn more biomedcentral.com/submissions 